\title{
PURSUING A CAREER IN ENDODONTICS
}

\section{By Lorna Gladwin}

$\mathrm{N}$ avigating which pathway to follow post undergraduate training is daunting. In my $4^{\text {th }}$ and $5^{\text {th }}$ year of dental school, I started to develop a passion for endodontic treatment. I would look forward to any lectures or teaching in this area, especially any clinical work I could carry out, I found myself in the urgent care clinic actively seeking patients who required root canal treatment just so I could do more endo, which made me consider pursuing a career in Endodontics.

\section{Where to start?}

Not every student who leaves dental school knows exactly where they want their career to take them, and there is absolutely nothing wrong with that, you have time to figure it out. But if similar to me, you are pretty sure you want to head down a certain path, it's great to get a head start with the things that will make you a perfect candidate in the future.

\section{Utilising the vast university network}

If you are still currently studying at university, you are in a very advantageous position, your university is full of experienced clinicians who have a wealth of knowledge and experience, use them to help you. Every dental school will have restorative and endodontic specialists who have all been in your position at some stage, approach them, show them your clinical work and ask for tips for improvement. It is also useful to keep a record log of cases you have completed with radiographs and reflections, don't just include the cases that went well, you often learn more from the cases that didn't go quite to plan. Make the most any spare time you have to take part in extra clinics, and ask to get involved with any research they may be carrying out, don't be shy! Your tutors will be impressed with your enthusiasm and work ethic, and this will go a long way to show you are committed. Highlighting your interest and commitment to extra work early within dental school will stand you in good stead of winning university prizes, the British Society of Endodontics offers an undergraduate prize, the Pitt-Ford prize, which I was lucky to win and looks great on a CV.

\section{Choosing your DFT practice wisely}

The practice you choose to do your foundation training in really can be a great stepping stone in your career. With so many practices on offer, it's crucial to look out for the important aspects a practice can offer you, to enable you to get the most out of your year. Large staff rooms and early finishes are great, but don't let this encourage you into picking a practice for the wrong reasons. Look for larger practices offering a range of specialties and treatments, this gives you greater opportunities to shadow different clinicians, a range of clinical opinions, and increased access to gain as much knowledge from different sources as possible. The DF practice that I chose offers almost every specialty, I spent a significant amount of time in my first few months of DF shadowing the endodontic special interest, watching many referral cases including apexification of open apices, re-root treatments and instrumenting sclerosed canals. An invaluable experience.

\section{Routes of specialisation}

It's important to know there are a range of routes into a specialist career, one pathway may suit you better than another depending on finances, time restraints and experience. The three main routes include: postgraduate degrees such as a DClinDent course, these are generally a 3 year full time self-funded course; the second is via training pathways, such as the 5 year StR restorative pathway; the third being a special interest - these are becoming increasingly popular in dentistry, and whilst not on the specialist register, this option can still allow you to focus your work on endodontic treatment. Both the postgraduate degree and the StR training pathway have entry requirements of at least 2 years' experience after your initial dental degree, although it is generally accepted that 3-4 years post graduate experience is the most ideal, usually in the forms of DCT $1 / 2 / 3$ sometimes with a combination of associate positions.

\section{Enhancing your employability}

Your CV and portfolio is your evidence base for all the hard work and commitment you have put in to get where you want to be, so you want to ensure it's a good reflection. Things that look great on a CV include publications, you get increased 'points' for being the first author, so try and get involved with some research early in your career. Audits you have undertaken look great too, along with any presentations you have done at regional, national or international level. Postgraduate qualifications such as the MJDF/MFDS are pretty much mandatory for specialist applications now, my advice would be to do these as soon as you can after graduating, as a lot of the content is very similar to finals and will be fresh in your mind. Undertaking CPD in the field you are interested in is important too, this could be webinars or online content, but also reading key endodontic journals and papers, such as the famous Krasner and Rankow pulp chamber anatomy paper.

Lastly, network. Reach out to people that are in the field you aspire to be in, engage with as many dental professionals as you can, you'd be surprised at how many people are willing to help.

Lorna Gladwin 